\title{
Mamoru Kawaguchi: Master of motion and lightness of structures
}

\author{
Carlos Lázaro
}

\begin{abstract}
Mamoru Kawaguchi (1932-2019) was one of the great structural engineers of the late 20th century. He developed his career mostly in Japan and he has also superb works in China, Singapore and Spain. The spectrum of his structures is manifold: he designed shells, space frames, inflatable structures, tension structures, timber-steel hybrid systems and so on. With them, he conceived and provided the bones and muscles of sports halls, exhibition halls, museums, railway stations, towers, bridges and sculptures. Kawaguchi collaborated with some of the best architects of his time: Kenzo Tange, Arata Isozaki and Kazuyo Sejima just to cite some of the internationally most renowned. For his works, he was awarded many times in Japan, as well as internationally (the Architectural Institute of Japan award, the International Association for Shell and Spatial Structures Torroja Medal, the International Association for Bridge and Structural Engineering International Award and many others). In this article, I review Mamoru Kawaguchi's main professional and academic achievements, and discuss his design philosophy, sources of inspiration and means to develop his ideas from my own personal experience.
\end{abstract}

\section{Keywords}

inflatable structures, International Association for Shell and Spatial Structures, Mamoru Kawaguchi, pantadome system, philosophy of structures, tension structures, timber-steel hybrid systems

\section{Introduction}

Mamoru Kawaguchi, one of the great structural engineers of the late 20th century, was born in Fukui in 1932. During his childhood and adolescence, the Kawaguchi family was hit by the destruction caused by World War II (WWII) and later by an earthquake; these dramatic events had undoubtedly an impact on his mind-set and career. He graduated at the University of Fukui in 1955 and was awarded a master's degree in engineering at the University of Tokyo in 1957.

His professional activity started under the mentorship of Professor Yoshikatsu Tsuboi - virtually the most important personality of the post-WWII Japanese structural engineering scene. They became close collaborators in many works. The most famous are the Yoyogi Stadiums for the 1964 Tokyo Olympics, designed by the great architect Kenzo Tange, for which Tsuboi was the structural designer, and Kawaguchi the chief engineer (Image 1). The report on the structural design, published in two parts in the Bulletin of the International Association for Shell and Spatial Structures (IASS) $)^{1,2}$ is a masterpiece of technical literature that honours the design and construction.

Mamoru Kawaguchi founded his design office, Kawaguchi \& Engineers, in 1964, where he continued collaborating with Yoshikatsu Tsuboi and Kenzo Tange. The international Expo '70, in the city of Osaka, with the theme 'Progress and Harmony for Mankind' was the fertile environment in which Kawaguchi developed several of his masterpieces: the Grand Roof (Image 2) - a huge space frame with inflatable cushions as roof cladding, in collaboration again with Tsuboi and Tange - and two pneumatic

Universitat Politècnica de València, Spain

Corresponding author:

Carlos Lázaro, Departamento de Mecánica de Medios Continuos y

Teoría de Estructuras, Universitat Politècnica de València, Camino de

Vera s/n, 46022 València, Spain.

Email: carlafer@mes.upv.es 


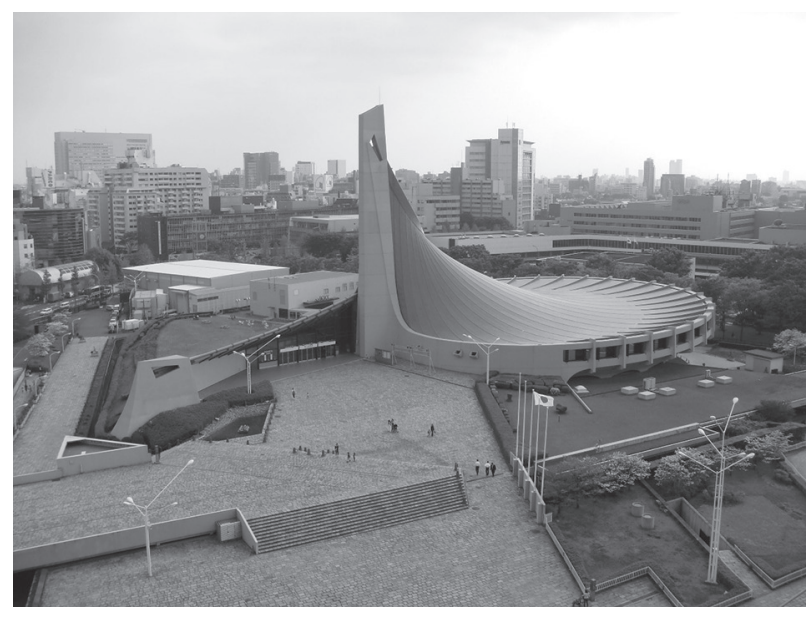

Image I. Second Yoyogi Stadium, Tokyo (1964). Photo credit: Juliane Petri.

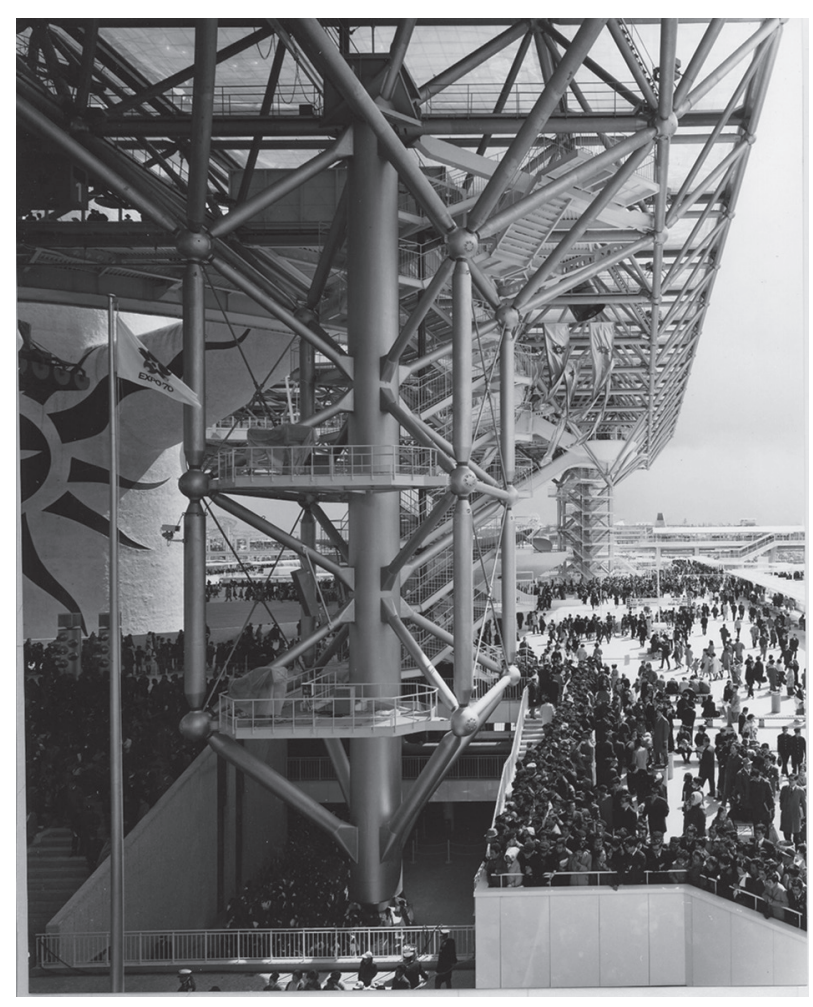

Image 2. Grand Roof for the Expo '70, Osaka (1970). Courtesy of Kawaguchi \& Engineers.

structures ahead of their time: the floating pavilion and the Fuji pavilion (Image 3) in collaboration with the architect Yutaka Murata. Other remarkable inflatable structures followed in the next decades as a result of the collaboration with Murata.

In 1977, he started a fruitful cooperation with Arata Isozaki - recently a Pritzker Prize laureate - designing the cable stayed roof for the West Japan General Exhibition

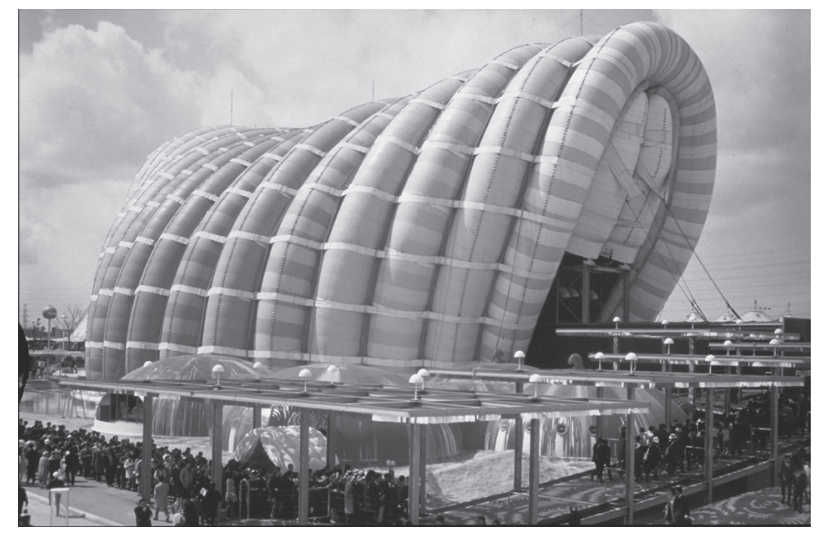

Image 3. Fuji Pavilion for the Expo '70, Osaka (1970). Courtesy of Kawaguchi \& Engineers.

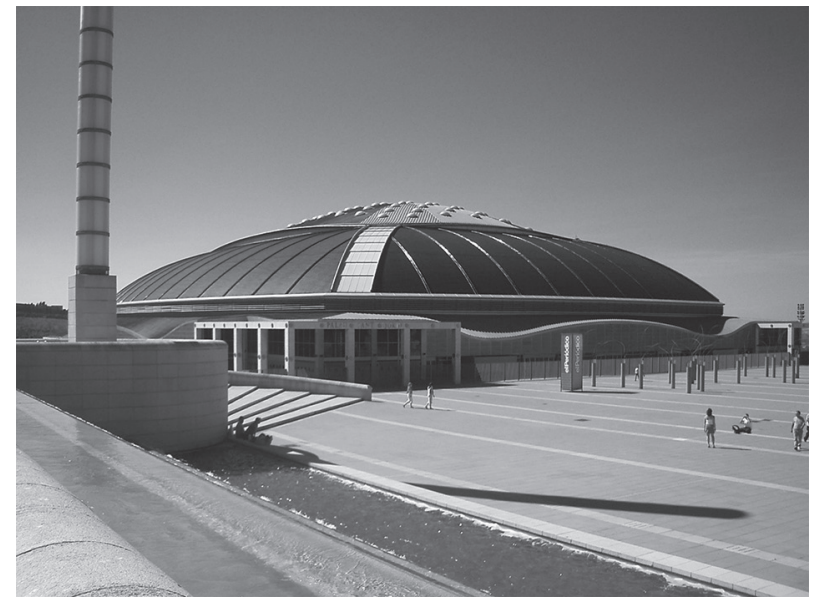

Image 4. Palau Sant Jordi, Barcelona (1992).

Photo credit: Toshiaki Tange.

Centre in Fukuoka. Other remarkable works with Isozaki were the Expo '90 Water Pavilion and International Friendship Pavilion in Osaka, the Kitakyushu International Convention Hall in Fukuoka, the Sant Jordi Sports Palace in Barcelona, Spain (1992) (Image 4) and more recently, the Ceramic Park Mino museum (2002) and the Cultural Centre in Shenzen, China (2008).

The Pantadome system is possibly the most famous of Kawaguchi's breakthroughs. It exploits motion as a benefit during construction: the roofing structure is designed to be a mechanism with one degree of freedom prior to its full completion. It is built near the ground level in a 'folded' configuration and then lifted up to reach the unfolded final shape; at this point, structural members are added to obtain a full stable system. The concept appears to be a simple one. The materialization, however, is complex: a proper way to split the system into movable parts of suitable dimensions must be found, and a careful detailing of rotational joints and of the lifting system is crucial for a smooth 


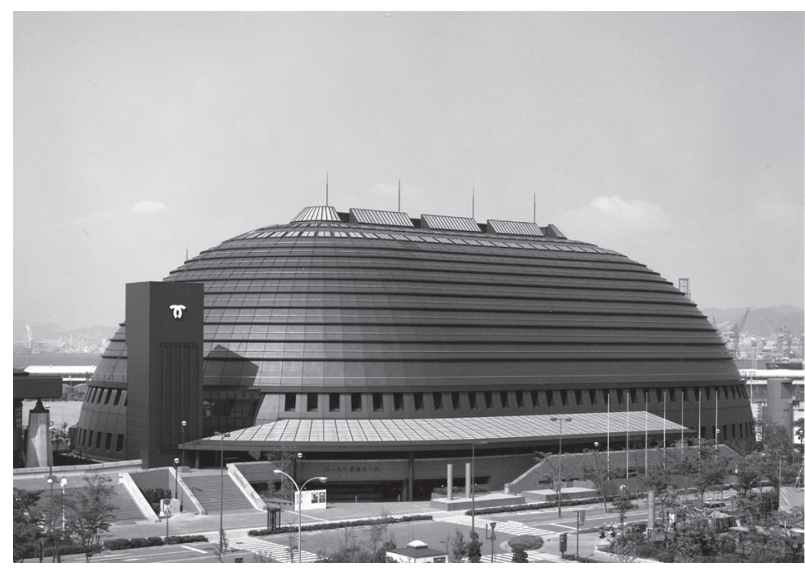

Image 5. World Memorial Hall, Kobe (1984). Courtesy of Kawaguchi \& Engineers.

deployment. The possibility to build the structure and large parts of the roof cladding near the ground means increased security levels and better control of the assembly process.

The first Pantadome was the World Memorial Hall in Kobe (1984) (Image 5). Altogether, Kawaguchi designed and had realized eight structures based on the Pantadome system, including the Singapore National Indoor Stadium (1989) with Kenzo Tange, the already mentioned Sant Jordi Sports Palace in Barcelona and the Nara Centennial Hall (1998), both with Arata Isozaki.

The Memorial Hall in Kobe also started another series of remarkable works with the architectural design firm Showa Sekkei that comprised several sports halls, among them the Namihaya Dome in Osaka (1996) - another Pantadome with an inclined lifting process.

In the 1990s and the first decade of the 21st century, Kawaguchi experimented with hybrid systems like the steelstone footbridge in Beppu, two railway stations (Hyuga and Kochi), a gymnasium in Gunma and a sports hall in Kagoshima with timber-steel hybrid roofs (Image 6). He also designed sculptures, towers, a bridge that includes a Ferris wheel and a variety of different structures.

The impact, the quality and the innovative character of Mamoru Kawaguchi's projects can be stated just by recalling that he collaborated as structural engineer with four Pritzker Prize laureates: in addition to the many works with Kenzo Tange and Arata Isozaki, he also collaborated with Fumihiko Maki (the Foreign Pavilion for the '85 Tsukuba Expo) and Kazuyo Sejima (Onishi Hall in Gunma, 2004). He was selected 'among the most distinguished structural engineers active in design in the world ${ }^{3}$ to deliver one of the 'Felix Candela Lectures' at the MoMA in New York City in 2001, the same year as he was awarded the Eduardo Torroja Medal, the highest recognition of the IASS.

In parallel with his professional activity, Mamoru Kawaguchi developed a successful academic career, earning his $\mathrm{PhD}$ at Tokyo University in 1966 and becoming a

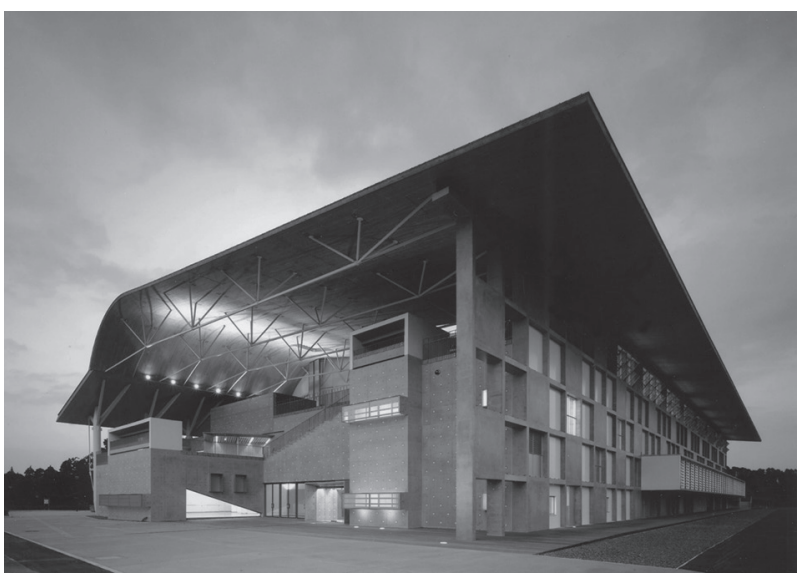

Image 6. Aira Gymnasium, Kagoshima (2004).

Photo credit: Hiroshi Hito, Nikkei Architecture, 3I October 2005. Courtesy of Kawaguchi \& Engineers.

Professor at Hosei University in Tokyo in 1972. He was awarded an honorary doctorate in engineering by the University of Stuttgart in 1997 and a second one by the Slovak University of Technology in Bratislava in 1998.

The IASS, the international association founded by Eduardo Torroja in 1959, constituted a privileged forum where Mamoru Kawaguchi could present his scientific and technologic developments, as well as his design philosophy. He was an active contributor to the IASS Journal, to the Working Group 8 on Metal Spatial Structures and to uncountable IASS Symposia. He became twice President of the IASS (1990-1991 and 2000-2006).

\section{Design philosophy}

My first recollection of Mamoru Kawaguchi's work was the article he wrote for a Spanish specialized journal in 1988 on how structures can enhance the architectural expression of buildings. ${ }^{4}$ At that time, he had just conceived the Pantadome structure of the Palau Sant Jordi for the Barcelona 1992 Olympics. Through this work, and probably thanks to the diffusion of his thinking on the philosophy of structures through his article, he became a much respected and admired personality by structural engineers in Spain. After Eduardo Torroja's breakthroughs in the design and construction of concrete shell structures, Spanish flagship structural designers in the 1960s-1980s excelled mostly in bridge design. Therefore, Kawaguchi's thoughts - and his realization in Barcelona - opened new perspectives and inspired a young generation of Spanish engineers.

Through Professor Yoshikatsu Tsuboi, who 'was very much impressed by Torroja's way of thinking, ${ }^{5}$ Kawaguchi became acquainted with the Spanish master's Philosophy of Structures. Torroja's principles were largely influenced by the Modern Movement and claimed austerity, simplicity 
and structural function as virtues. Kawaguchi reviewed them in a wider cultural context using the pagoda as the archetype of Eastern architectural expression and found that there are superb examples of traditional Japanese timber constructions in which the architectural expression does not reflect the flow of forces intentionally and can deceive an untrained observer. This fact was defined by him as 'indeterminacy in the expression of architectural systems', ${ }^{4,6}$

Despite this observation, most of Kawaguchi's works are excellent examples of honest architectural expression of the structure - and structural expression of architecture as well. In this way, he returns to the principles of Modernism. His concern about the way to enhance architectural forms through the expression of the structure made him become - in words of Guy Nordenson - 'a great collaborator'. ${ }^{3}$

His advice that 'structural engineers (and architects) should be trained to penetrate the load carrying mechanism of a structure before they begin to calculate it ${ }^{6}$ highlights a very topical point: clarity of the structural concept is crucial in the era of computation.

His works convey, in my view, a connection with Japanese traditional construction. In some cases, it is implicit in the shape of the building (the Yoyogi Stadium, the Singapore Stadium or the Musashi Hall) where he conceives the skeleton for the form devised by the architect, which triggers his reflections on Japanese structural craft. In other works, local tradition is explicitly found in the materiality, as in his timber structures, or the stone deck and the ceramic ornaments of the joints of the Inachus footbridge in Beppu.

In contrast, another key idea that pervades Kawaguchi's work is the willingness to express progress of society through technological advance. From the 1960s, the design, manufacturing and production of space grids experimented rapid advances. Kawaguchi became aware of the possibilities that emerging CAD technologies introduced in shaping curved grids for architectural forms:

By introduction of electronic technologies [. . . ] into production processes, mass production of our age has [made] possible to produce small quantities of goods in numerous varieties. If this production system is applied to fabrication of space frame members, great freedom in structural forms may be possible. ${ }^{4}$

In many of his works, especially in the space frame of the Grand Roof and in the Pantadome systems, he took advantage of state-of-the-art space grid technology and contributed greatly to its advance. This is reflected in his contribution to the IASS Working Group 8 report on "Analysis, design and realization of space frames" ${ }^{17}$ and in other publications of the 1980s and 1990s. ${ }^{8,9}$

In that spirit as well, his inflatable structures - starting with the pavilions for the ' 70 Osaka Expo - are certainly

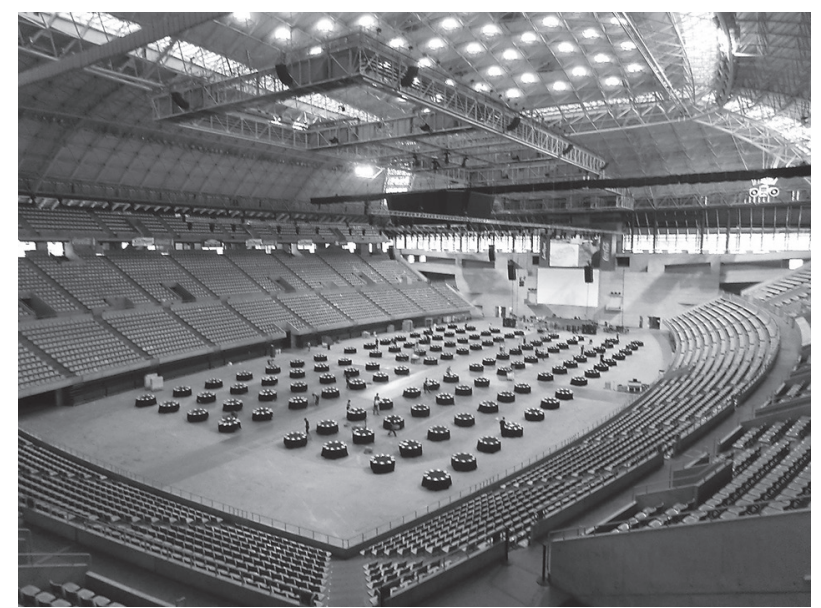

Image 7. Interior of the Sant Jordi Sports Palace. Photo credit: Toshiaki Tange.

best examples of his keenness to experiment and his courage to be on the forefront of the technology of his time.

If I had to choose a common feature of his designs, I would mention lightness. It is obvious in the case of the pneumatics and a requirement for economy in the Pantadome roofs. Even the largest roofs convey a sense of lightness, especially when experienced from the inside (Image 7).

For discussing the meaning of conceptual design ${ }^{10}$ in the 1996 IASS Stuttgart Symposium, Kawaguchi prepared a list of the forerunners in structural design and gave hints about their sources of inspiration and means to develop their ideas. In the next sections, I will follow his suggestion and provide my personal vision of his sources of inspiration and means of developing his ideas.

\section{Sources of inspiration}

I remember well the first time I attended one of his lectures, at the IASS 1999 Madrid Symposium. The topic of the lecture was the new 'suspendome' system devised by him. A novel hybrid composed of a shallow steel lattice spherical dome on top and a lower cable-strut (Geiger-type) system. Kawaguchi explained the construction of the Fureai dome, as well as analytical and experimental results needed to prove strength and stability. But a substantial part of his lecture was devoted to explaining the basic statics of the 'suspendome', the underlying physics of the new system.

Listening to many of his lectures, I always observed a common thread in the way he introduced every project and every topic: he always called attention to the fundamental principle on which a specific realization based. For example, the less-than-evident peculiarities of the statics of airinflated structures, or the pendulum principles applied to seismic isolation ... Straightforward explanations that supported complex realizations. 


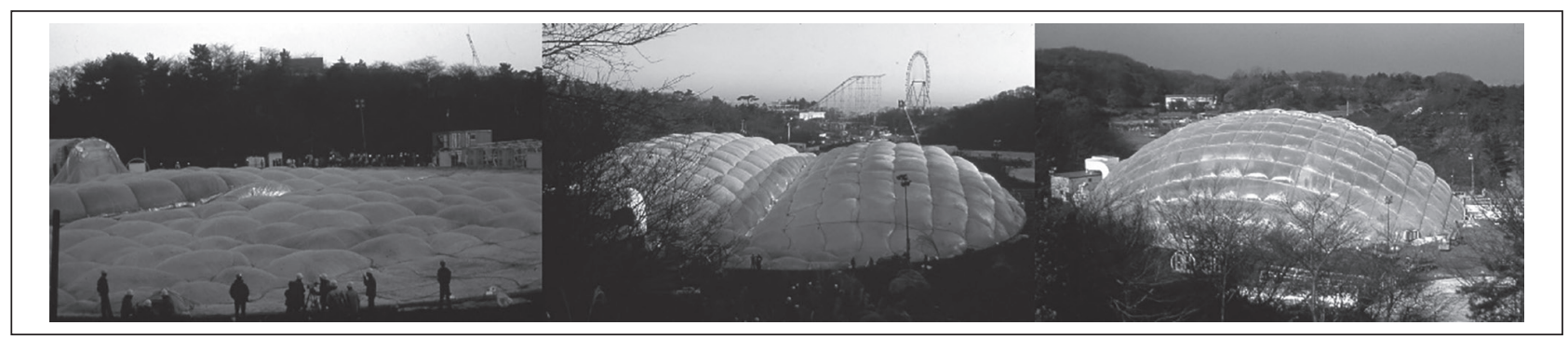

Image 8. Inflation of the I2th World Orchid Conference Pavilion, Kanagawa (1987).

Courtesy of Kawaguchi \& Engineers.

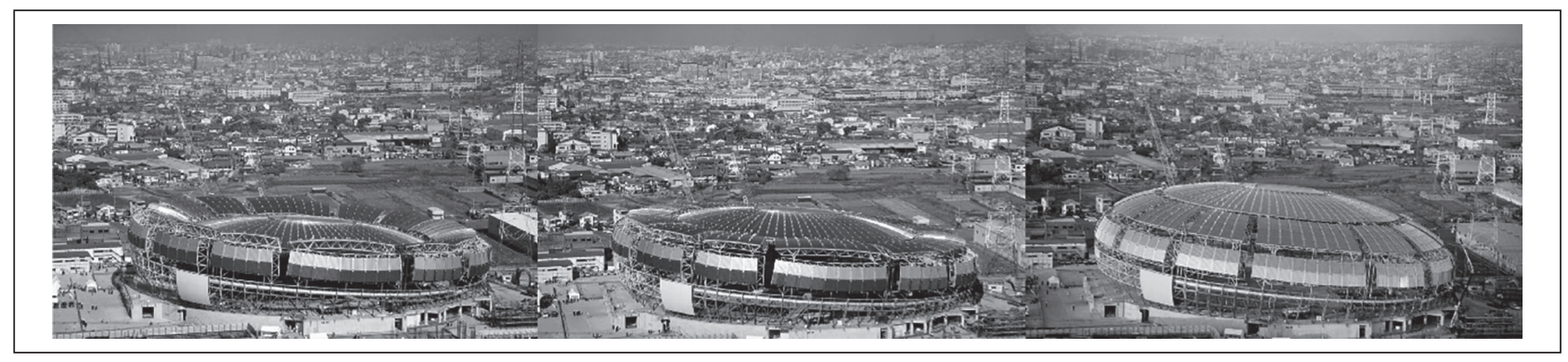

Image 9. Deployment of the Namihaya Dome, Kobe (1996). Courtesy of Kawaguchi \& Engineers.

Therefore, I claim that physical principles are Mamoru Kawaguchi's main sources of inspiration.

In a round table at the IASS 2005 in Bucharest on the topic of structural form-finding, he defined (his) inflatables as 'let-it-be' structural forms by stating that 'only the governing principles are given, and the resulting forms are observed'. Obviously, the shape of the Fuji Pavilion or the World Orchid Pavilion (Image 8) was by no means a result of chance, but his hyperbolic statement illustrates very well my claim.

In many cases, inspiration came from the principles of motion. Motion is inherent to the process of building. We find motion in the inflation process of his pneumatic structures, as well as in the deployment of his Pantadome systems.

Nowadays, we often watch stop motion films in which objects are manipulated in small increments and photographed to create the illusion of independent motion. When we analyse the sequence of deployment of any of his eight Pantadomes, we can readily compare it with a stop motion film: the structure takes various shapes during the process; after every stroke of the jacks, it stops; then, pistons are retracted and the system is pushed (or pulled) again to the next 'photogram' (Image 9). As pointed out by Nordenson, ${ }^{3}$ the sequence has something theatrical. It also puts the (incomplete) mechanism during the process on an equal footing with the finished structure.

Inflation of pneumatics is a smooth process; deployment of a Pantadome is a stepped sequence, but both are

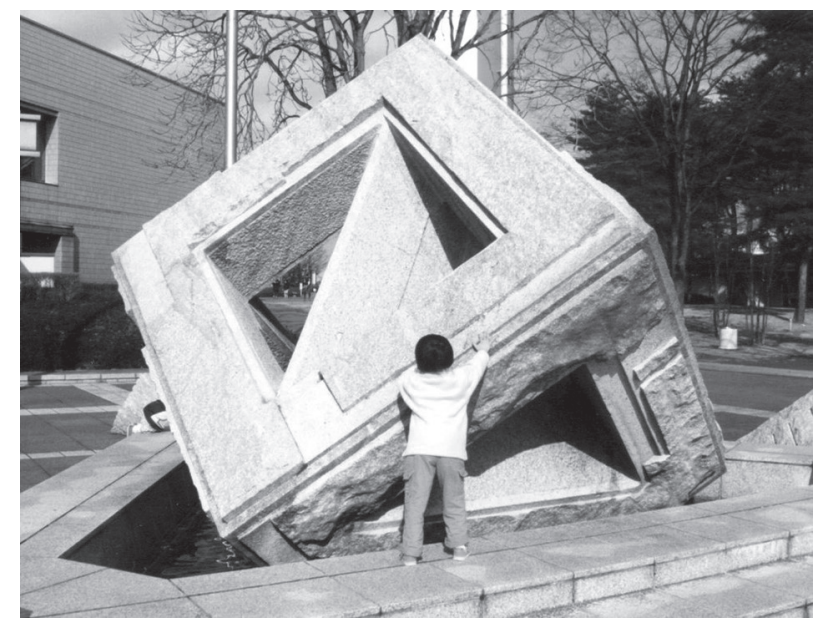

Image 10. Yurugi-Ishi, Tsukuba (1984).

Courtesy of Kawaguchi \& Engineers.

bounded in time: they stop when the structure reaches its target shape. In contrast, three of his works for which unbounded, oscillatory motion is an advantage follow:

The first one is the sculpture Yurugi-Ishi (rocking stone) in Tsukuba (1984) (Image 10). A cubic stone block, sculpted by Tomihisha Handa, rests on a spherical hinge on top of a column. A small child can make the sculpture oscillate.

In the ceramic museum Mino in Gifu (2002), designed in collaboration with Arata Isozaki, the fragile ceramic 
items of the exhibition were protected against earthquakes by suspending the floor with hinged rods from rigid frames. The whole floor can oscillate as a pendulum. When the building is hit by an earthquake, the rigid frames vibrate with the soil and the suspended floor acts as a push-pull oscillator. In combination with adequate damping, shock waves are strongly mitigated.

The last example is the lightest possible structure: a 'jumbo koinobori' or giant flying carp (100 m long) made of cotton fabric - the same used for small 'koinoboris' (Image 11). After some failures, the city of Kazo consulted Kawaguchi in 1988. Since then, the giant carp swims majestically every year to celebrate Children's day.

\section{Means to develop his ideas}

The start of Mamoru Kawaguchi's career, first as a disciple and then as chief engineer of Professor Tsuboi's Institute, was deeply influenced by his mentor's command of shell theory and mathematical analysis. The collaboration with Professor Tsuboi positioned him at the frontiers of the structural developments of his time. He

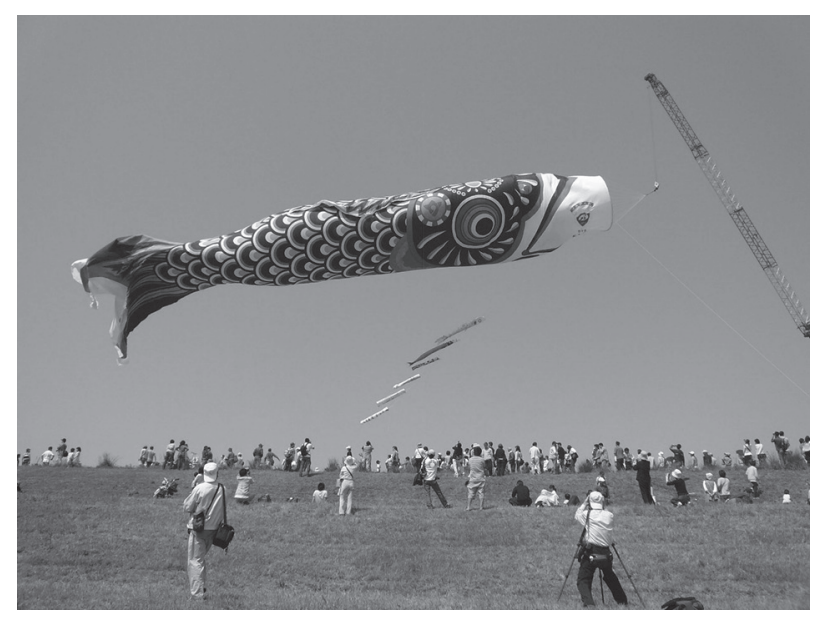

Image I I. Jumbo koinobori, Kazo (1988).

Photo credit: Takeshi Kirihara. Courtesy of Kawaguchi \& Engineers. worked on extremely complex problems in a time when there was 'no calculating machine that could be called a computer'. ${ }^{11}$ The semi-rigid hanging roofs for the Yoyogi stadiums, or the Grand Roof space frame, required a combination of complex analytical skills, painstaking experimentation in reduced models and sound engineering judgement. ${ }^{1,2}$

A less known example of his use of analytical tools is the development of the 'the shallowest possible pneumatic': the shape of a dome with circular plan, vertical tangents along the perimeter and minimum possible height. He analysed this shape and its properties by means of the membrane theory. ${ }^{12}$ He applied this shape in the construction of five fibre reinforced plastic (FRP) domes with $8 \mathrm{~m}$ diameter in plan for the ' 75 Okinawa Expo, and also in the erection of a thin metal dome by means of an inflatable membrane wherein thin stainless-steel strips were laid radially on the deflated membrane and then, after inflation, the strips were connected to the base and to each other.

We see that in his early works, he used a combination of mathematical analysis (applied to membrane and shell theory) and laboratory testing with physical models as design tools. However, even in the case of such a rational formfinding process as in the shallowest pneumatic, he made use of concept models: two inflatables aimed at testing the principles, not at making precise measurements (Image 12).

In 2009, on the occasion of the 50th Anniversary Symposium of the IASS, together with Alberto Domingo, we organized a Kawaguchi exhibition in Valencia. During the preparation of the exhibition, I was looking for sketches drawn by him. I soon realized that his 'sketches', his way of expressing his concepts, were in fact his models. Models were used as tools for thinking, as instruments to grasp three-dimensional structural behaviour. Not intended to measure, but instead to understand the concept, to appreciate the spatial quality, and ultimately to 'touch and feel' the deformation. In his own words, touch and feel models (as he named them) '. . . are suitable for the designer to intuitively understand the force flow in the structure he is going to create' (Image 13). ${ }^{13}$

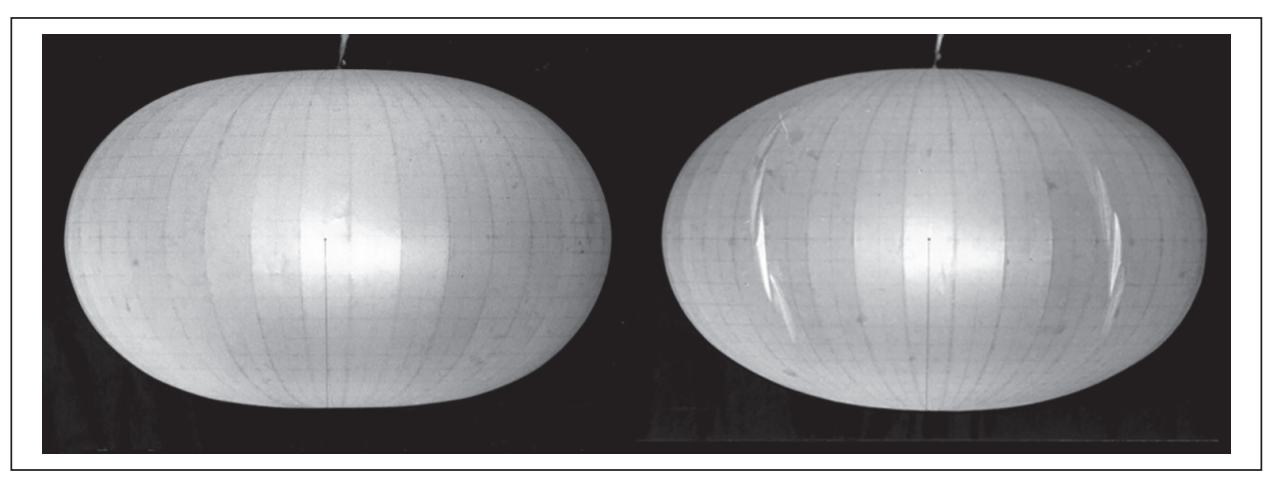

Image 12. Concept models for the shallowest pneumatic. Courtesy of Kawaguchi \& Engineers. 


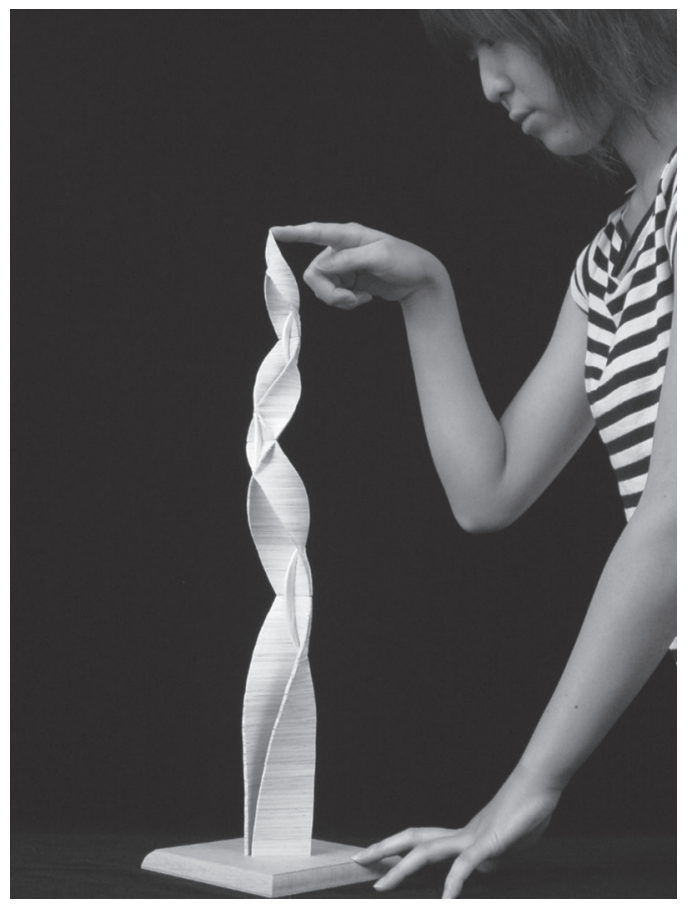

Image 13. Model of the Tianjin Tower.

Courtesy of Kawaguchi \& Engineers.

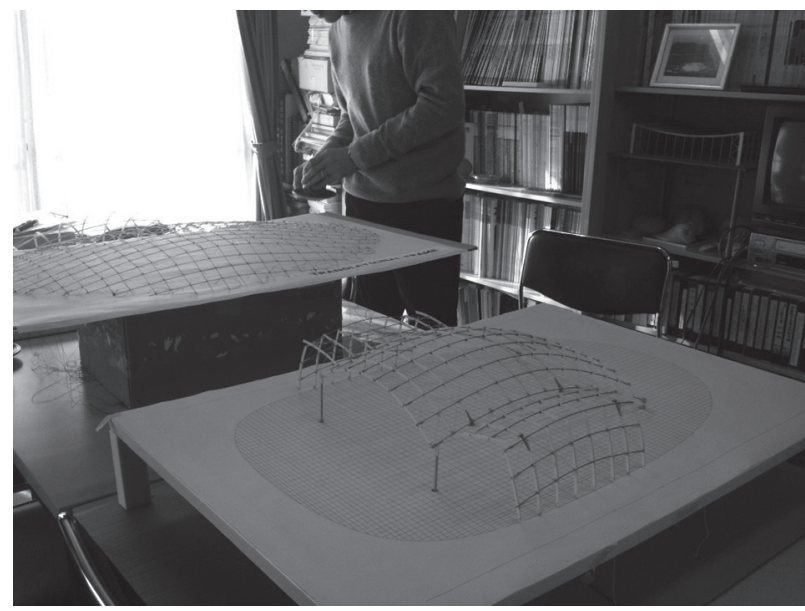

Image I4. Working models at Kawaguchi \& Engineers. Photo credit: Juliane Petri.

Touch-and-feel models are part of the design process at Kawaguchi \& Engineers. They help understanding principles, visualizing volumes, feeling the behaviour and connecting analysis to reality. Models were Kawaguchi's principal means to develop ideas (Image 14).

The Valencia exhibition gathered the impressive collection of models that were built in his office during many years. The public could interact with the models and understand how structures deform or the kinematics of Pantadome systems (Image 15). The book of the exhibition includes a complete account of Kawaguchi's main projects up to $2008 .^{14}$

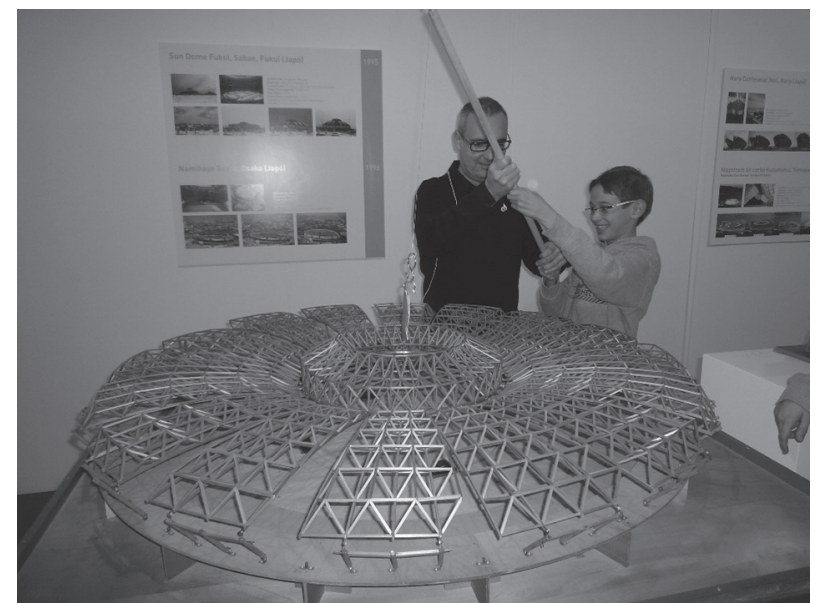

Image I5. Model of the Pantadome for the Sun Dome in Fukui.

Photo credit: Juliane Petri.

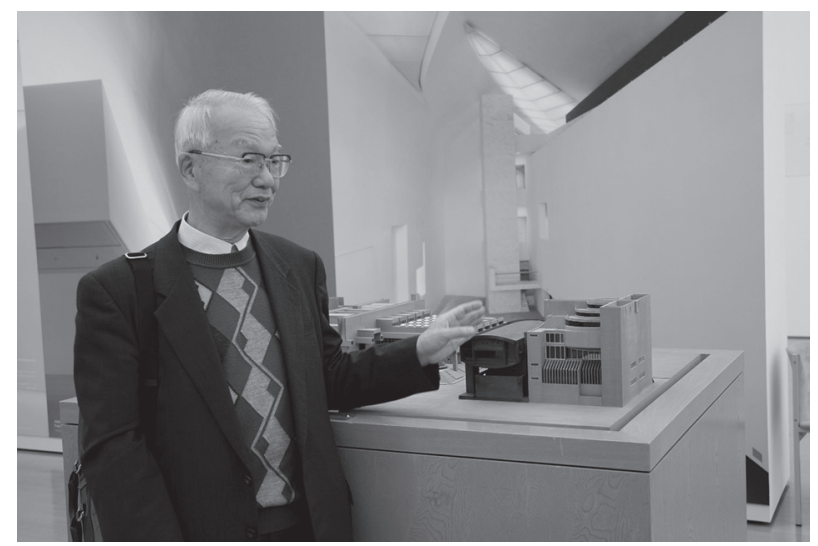

Image 16. Mamoru Kawaguchi at Gunma Museum (2008). Photo credit: Juliane Petri.

\section{Final remarks}

I have been extremely fortunate to have had the opportunity to collaborate with Mamoru Kawaguchi in his last Pantadome roof in Xàtiva (Spain) ${ }^{15}$ and also in a large glazed dome for a public building in Georgia. I could appreciate his way to approach engineering problems, the clarity of his ideas and the skills and effectiveness of his team to produce the design. I learnt that innovation should be sought in every project and I admired his attention and firmness when controlling construction details. I enjoyed our discussions, his explanations and his humour: I remember well his informal comment when I referred to one of the car overpasses that one sees often in Tokyo street junctions: '. . . hmm . . . too heavy'. Through his love for Japanese traditional singing, I also became acquainted with a very particular feature of Japanese culture (Image 16).

He would certainly be glad to have his team properly acknowledged; therefore, I wouldn't want to finish 
without mentioning the Kawaguchi \& Engineers team members I met in those years: Mr Yushi Aso, Mr Minoru Matsui, Ms Chie Matsuo, Mr Ryoma Murata and Ms Ikuko Horie.

Professor Mamoru Kawaguchi's design philosophy and superb realizations have been - and will continue to be - a tremendous source of inspiration for structural engineers and architects. He will always be remembered as the master of motion and lightness of structures.

\section{Acknowledgements}

I am deeply grateful to Professor Ken'ichi Kawaguchi and to Kawaguchi \& Engineers for granting permission to reproduce graphic material from their archive, as well as to Mr Toshiaki Tange, head of the Arata Isozaki office in Barcelona, for providing pictures of the Sant Jordi Sports Palace.

\section{Declaration of conflicting interests}

The author(s) declared no potential conflicts of interest with respect to the research, authorship and/or publication of this article.

\section{Funding}

The author(s) received no financial support for the research, authorship and/or publication of this article.

\section{ORCID iD}

Carlos Lázaro iD https://orcid.org/0000-0001-7255-7068

\section{References}

1. Tsuboi Y and Kawaguchi M. Design problems of suspension roof structure: Tokyo Olympic Swimming Pools (I). Bull Int Assoc Shell Spat Struct 1966; 27: 3-30.

2. Tsuboi Y and Kawaguchi M. Design problems of suspension roof structure: Tokyo Olympic Swimming Pools (II). Bull Int Assoc Shell Spat Struct 1966; 28: 3-24.
3. Nordenson G. Constellations. In: Nonderson G (ed.) Seven structural engineers: the Felix Candela lectures. New York: The Museum of Modern Art, 2008, pp. 9-27.

4. Kawaguchi M. Cómo pueden las estructuras realzar las formas arquitectónicas? (How can structures enhance architectural forms?). Obra Púb 1988; 7-8: 60-77 (in Spanish and English).

5. Kawaguchi M. Yoshikatsu Tsuboi, distinguished researcher, warm-hearted teacher and talented structural designer. Int $J$ Sp Struct 2006; 21(1): 31-41.

6. Kawaguchi M. Tension structures and their form. Bull Int Assoc Shell Spat Struct 1979; 20(2): 25-39.

7. Tsuboi Y. Analysis, design and realization of space frames (Report by IASS Working Group 8 on spatial steel structures). Bull Int Assoc Shell Spat Struct 1984; 25(2): 1-114.

8. Kawaguchi M. A review of recent development of steel space structures in Japan. Bull Int Assoc Shell Spat Struct 1988; 29(1): 43-62.

9. Kawaguchi M. Space structures with changing geometries. Bull Int Assoc Shell Spat Struct 1990; 31(1-2): 33-45.

10. Kawaguchi M. Memorandum about conceptual design. Bull Int Assoc Shell Spat Struct 1996; 37(1): 27-29.

11. Kawaguchi M. The design of structures: from hard to soft. In: Nonderson G (ed.) Seven structural engineers: the Felix Candela lectures. New York: The Museum of Modern Art, 2008, pp. 103-121.

12. Kawaguchi M. The shallowest possible pneumatic. Bull Int Assoc Shell Spat Struct 1977; 28(1): 3-11.

13. Kawaguchi M. Physical models as powerful weapons in structural design. In: IASS symposium on shell and spatial structures from models to realization, Montpellier, September 2003.

14. Lázaro C, Domingo A, Kawaguchi K, et al. Mamoru Kawaguchi, ingeniero de estructuras: Innovación y tradición en el proyecto de estructuras (Book of the exhibition). València: Editorial Universitat Politècnica de València, 2009 (Texts in Spanish, Valencian and English).

15. Lázaro $C$ and Domingo A. Detailing and construction of the Pantadome roof structure for a bullring in Xàtiva (Spain). Int J Sp Struct 2010; 25(4): 229-241. 